\title{
BMJ Open Associations between the SHARE frailty phenotype and common frailty characteristics: evidence from a large Danish population study
}

\author{
Katja Kemp Jacobsen, ${ }^{1}$ Randi Jepsen, ${ }^{1}$ Maurice A Lembeck, ${ }^{2}$ Charlotte Nilsson, ${ }^{3}$ \\ Ellen Holm ${ }^{4,5}$
}

To cite: Jacobsen KK, Jepsen R, Lembeck MA, et al. Associations between the SHARE frailty phenotype and common frailty characteristics: evidence from a large Danish population study. BMJ Open 2019;9:e032597. doi:10.1136/ bmjopen-2019-032597

- Prepublication history for this paper is available online. To view these files, please visit the journal online (http://dx.doi. org/10.1136/bmjopen-2019032597).

Received 26 June 2019 Revised 16 September 2019 Accepted 17 September 2019

Check for updates

(c) Author(s) (or their employer(s)) 2019. Re-use permitted under CC BY-NC. No commercial re-use. See rights and permissions. Published by BMJ.

${ }^{1}$ Lolland-Falster Helath Study, Nykøbing F Sygehus, Nykobing, Denmark

${ }^{2}$ Medical Department, Nykobing F Sygehus, Nykobing Falster, Denmark

${ }^{3}$ Department of Public Health, University of Copenhagen, Copenhagen, Denmark

${ }^{4}$ Internal Medicine, Nykøbing F Sygehus, Nykobing, Denmark

${ }^{5}$ Institute of Clinical Medicine, University of Copenhagen, Kobenhavns, Denmark

Correspondence to

Ellen Holm;

ellh@regionsjaelland.dk

\section{ABSTRACT}

Objectives Frailty is a major clinical geriatric syndrome associated with serious adverse events including functional disability, falls, hospitalisation, increased morbidity and mortality. The aim of this study was to study associations between a frailty phenotype and frailty characteristics well known from the literature.

Design Registry-based cross-sectional study.

Setting The target population consists of inhabitants above the age of 50 living in the Danish municipalities of Lolland and Guldborgsund. Excluded are incapacitated people, inhabitants unable to understand Danish or English and inhabitants without a permanent residence.

Participants 7327 individuals aged $50+$ years were included.

Outcome measures We examined associations between the frailty measurement and factors known to be associated with frailty: sex, age, income insufficiency, education, comorbidity, self-assessed health, morbidity and mortality.

Results 7327 individuals aged $50+$ years were included. Of these, $6.5 \%$ had $\geq 3$ frailty components (frail), $46.7 \%$ had 1-2 components (prefrail) and $46.9 \%$ had none (non-frail). Those who were frail were older and more likely female than those who were non-frail or prefrail. There was a stepwise decrease in educational level, and in self-assessed health with increasing frailty status, and a stepwise increase in difficulty in making ends meet, number of hospital contacts and mortality with increasing frailty status, $p<0.0001$ for each comparison. Compared with individuals who were non-frail, mortality was higher among those who were prefrail (HR: 2.90; $95 \% \mathrm{Cl}: 1.30$ to 6.43 ) or frail (HR: $8.21 ; 95 \% \mathrm{Cl}: 3.37$ to 20.0 ).

Conclusions Based on these findings, we consider the Lolland-Falster Health Study frailty assessment a valid instrument demonstrating the same characteristics as other validated frailty measures concerning associations with sex, age, income insufficiency, education, comorbidity, self-assessed health, morbidity and mortality.

Trial registration number NCT02482896.

\section{BACKGROUND}

Frailty is a major clinical geriatric syndrome associated with serious adverse outcomes including functional disability, falls,
Strengths and limitations of this study

- The frailty measurement studied has only minor deviations from a widely recognised instrument used in the Senior Health in Ageing and Retirement study in Europe.

- The frailty measurement was studied in a large representative population.

- The Lolland-Falster Health Study is cross-sectional but by coupling with national registries, we were able to follow the participants over time.

- Due to lack of follow-up data concerning morbidity, we assessed associations between morbidity and frailty by using data on morbidity during a period of 6 months before the frailty measurement.

hospitalisation, increased morbidity and mortality. The pathophysiology of frailty includes age-related decline in the function of multiple organ systems leading to insufficient homeostatic mechanisms and thereby increased vulnerability to minor stressor events. ${ }^{1}$ Two principally different approaches are used in order to operationalise the measurement of frailty. Fried et al described a physical frailty phenotype based on five criteria including exhaustion (fatigue), weight loss (unintentional), weakness, slowness and low activity. Individuals fulfilling three or more of the five criteria are defined as frail and individuals fulfilling $1-2$ as prefrail. ${ }^{2}$ If an individual is frail according to the physical frailty phenotype, it is not necessarily obvious without measurement of the five included criteria. In contrast, Mitnitski et al described frailty as an accumulation of health deficits occurring with ageing and operationalised this approach in the frailty index. ${ }^{3} \mathrm{~A}$ frailty index consists of a predefined list of deficits. The proportion of deficits present in a specific person defines the frailty index. If for instant the chosen list of deficits consists 
of 50 items, of which the individual has 10 , the frailty index of this individual is $10 / 50=0.2$. The frailty index includes traditional health items like medical diagnoses but also other factors describing cognitive function, social circumstances and functional loss. Although there is thus no universally accepted operational definition of frailty, the Fried frailty phenotype is widely used and validated in several studies. ${ }^{4-7}$

The Senior Health in Ageing and Retirement study in Europe (SHARE) is a population study including questions, which have been used to develop a ShareFrailty Instrument (SHARE-FI) ${ }^{8}$ Validation studies have demonstrated that SHARE-FI is associated with mortality ${ }^{9}$ and with loss of functional capacity. ${ }^{10}$

The SHARE study included in its first wave 1699 Danish citizens above the age of 50 . These participants were drawn by the Danish National Institute of Statistics in order to reflect the Danish population. The SHARE questionnaires were translated into Danish following recommendations from the SHARE organisation. ${ }^{11}$ The questions used in the SHARE-FI were chosen retrospectively based on their similarity to the items in the frailty phenotype originally developed by Fried $e t a l^{2}$

The Danish population study, the Lolland-Falster Health Study (LOFUS) ${ }^{12}$ includes frailty items almost the same as those used in the SHARE-FI.

\section{Epidemiology, morbidity and mortality associated with frailty}

A systematic review found the prevalence of frailty among individuals aged $65+$ varying between $4 \%$ and $59.1 \%$ with an overall weighted prevalence of $10.7 \%$. Prevalence increased with age and was higher in women. ${ }^{13}$ The prevalence of frailty in Europe among 7510 participants aged 65+ enrolled in SHARE 2004 varied between 8.6\% (Sweden) and $27.3 \%$ (Spain). The prevalence among 877 Danish participants aged 50-64 years was $3.0 \%$ and among 635 participants aged $65+12.4 \% 0 .^{8}$

Two meta-analyses including studies using the Fried phenotype found significant higher hospitalisation risk in frail compared with non-frail elderly individuals (OR: 1.49, CI: 1.26 to 1.76$),{ }^{14}$ and significant increased mortality (HR: 1.874 , CI: 1.635 to 2.150$).^{15}$

\section{Objectives}

The aim of this study was to examine whether the frailty measurement used in LOFUS was able to identify frail individuals. We did this by examining to what degree the frailty measurement is associated with factors known to be associated with frailty: age, sex, multimorbidity, level of education, income insufficiency, self-assessed health, morbidity and mortality. ${ }^{2} 16$

\section{DESIGN AND PARTICIPANTS}

LOFUS has been described in detail elsewhere. ${ }^{12}$ In summary, it is a household-based cross-sectional study including people of all ages. Lolland-Falster consists of two islands in the southern part of Denmark. It is a rural area where income is lower and life expectancy shorter than in the general Danish population. The target population for the present substudy consists of inhabitants above the age of 50 living in the Danish municipalities of Lolland and Guldborgsund. Excluded are incapacitated people, inhabitants unable to understand Danish or English and inhabitants without a permanent residence.

The data collection started in February 2016 and is still ongoing; with currently 7992 individuals aged 50+ years recruited.

\section{METHODS}

Frailty

LOFUS includes the following variables used to assess frailty:

1. Exhaustion/Fatigue: the criterion was fulfilled by answering yes in response to the question 'In the last month or so, have you had too little energy to do things you wanted to do?' (Yes/No)

2. Shrinking: the criterion was fulfilled by answering yes in response to the question 'What has your appetite been like? Do you feel a diminution in desire for food?' (Yes/No)

3. Weakness was derived from the highest of three consecutive dynamometer measurements of handgrip strength in the dominant hand applying gender and body mass index cutoffs set by Fried $e t a l .^{2}$

4. Slowness: a positive answer to either of the following two items 'Because of a health problem, do you have difficulty ([expected to last more than 3 months]) walking 100 meters or "climbing one flight of stairs without resting'?

5. Low activity was fulfilled in participants responding one to three times a month, hardly ever or never to the question 'How often do you engage in activities that require a low or moderate level of energy such as gardening, cleaning the car, or going for a walk?'

Individuals fulfilling 1-2 of the above-mentioned criteria were characterised as prefrail, while those fulfilling $3-5$ criteria were characterised as frail. If none of the criteria were fulfilled, individuals were characterised as non-frail.

Factors assessed for association with frailty, data from LOFUS The following factors were extracted from the LOFUS questionnaires: age, sex, self-assessed health, educational background, financial difficulties, comorbidity and mortality. Educational level was categorised according to highest obtained education into four categories: 'primary school', 'short education', 'medium higher education' and 'long higher education'.

Comorbidity was assessed by asking participants if they suffered from angina, migraine or headache, arthritis, cancer, diabetes, hypertension, chronic bronchitis, emphysema, chronic obstructive pulmonary disease, depression, anxiety, kidney disease, asthma, dementia or Parkinson's disease. Socioeconomic status was assessed by 
the question 'During the last twelve months, how often did you find difficulty in making ends meet?'

\section{Data from national health registers}

Every person residing in Denmark is uniquely registered in the Danish Civil Registration System (CRS). ${ }^{17}$ The LOFUS database receives daily updates from CRS on all inhabitants of Lolland-Falster regarding births, deaths, immigration and moving of residents. Individuals were followed up in CRS until date of death or February 2019. Additionally, we assessed data on hospitalisation by merging the LOFUS database with the Danish National Patient Register. ${ }^{18}$

Number of hospital contacts was defined as hospital contacts within 2 years prior to the date of participation in LOFUS. Hospital contacts were categorised as no admission days registered in the National Patient Register (ambulant contacts) or admission days registered (hospital admission).

\section{Sample size}

For the substudy on aging-related outcomes in LOFUS, that is among the $50+$ yearolds, the original idea was to study the association between social factors (socioeconomic position and social relations, respectively) and physical function and frailty. Initially, we performed power calculations for all social variables in relation to detection of their impact on physical function as well as frailty. The prevalence estimates used in these power calculations were calculated from previous Danish population surveys applying similar measures, and previous literature. ${ }^{161920}$ Based on these calculations, we requested inclusion of 5800 individuals aged $50+$, in order to detect an association between each of the social variables and physical function or frailty at a significance level of 0.05 and with $80 \%$ power. However, based on the power calculations performed for frailty as dependent variable, we only needed 1600 individuals aged $50+$ in order to detect an association between socioeconomic position and frailty at a significance level of 0.05 and with $80 \%$ power. Therefore, we found it feasible to perform this study when more than 7000 individuals aged 50+ were included, even though the LOFUS study is still recruiting.

\section{Statistical analysis}

For associations of frailty phenotype with demographic and health characteristics, and hospital contacts, the p-trend values based on the Cochran-Mantel-Haenszel test was used, using the cmh function in STATA/SE V.15.1. For associations between frailty phenotype and mortality, the Cox proportional hazard regression model, using length of follow-up as the time metric, estimated HRs and 95\% CI. The Cox model was adjusted for age group and sex.

\section{Patient and public involvement}

Patients and public were not involved in the development of this study.

\begin{tabular}{|c|c|c|c|}
\hline & $\begin{array}{l}\text { Total } \\
(n=7327)\end{array}$ & $\begin{array}{l}\text { Men } \\
(n=3498)\end{array}$ & $\begin{array}{l}\text { Women } \\
(n=3829)\end{array}$ \\
\hline \multicolumn{4}{|c|}{ Frequency of frailty components } \\
\hline Exhaustion & 41.5 & 38.8 & 43.9 \\
\hline Shrinking & 6.3 & 5.0 & 7.5 \\
\hline Weakness & 8.2 & 8.1 & 8.2 \\
\hline Slowness & 12.8 & 11.8 & 13.8 \\
\hline Low activity & 12.2 & 11.1 & 13.1 \\
\hline \multicolumn{4}{|c|}{ Number of frailty components } \\
\hline 0 & 46.8 & 49.7 & 44.2 \\
\hline 1 & 33.8 & 32.9 & 34.6 \\
\hline 2 & 12.9 & 11.8 & 13.9 \\
\hline 3 & 4.7 & 4.4 & 4.9 \\
\hline 4 & 1.7 & 1.1 & 2.1 \\
\hline 5 & 0.1 & 0.1 & 0.2 \\
\hline
\end{tabular}

\section{RESULTS}

Of a total of 7992 individuals 50+ years old, $656(12.2 \%)$ were excluded as they did not answer the questions on frailty. Nine individuals were considered not available for frailty measurement as they had three or more missing frailty components, leaving 7327 individuals for analysis. Of these, $6.5 \%$ had $\geq 3$ frailty components, $46.7 \%$ had $1-2$ components and $46.8 \%$ had none. The most frequent frailty component was exhaustion (41.5\%), followed by slowness $(12.8 \%)$ and low activity (12.2\%) (table 1$)$. Overall, $55.8 \%$ reported 'good' self-assessed health and $93.6 \%$ never had difficulty in making ends meet (table 2).

Those who were frail were older and more likely female than those who were non-frail or prefrail. There was a stepwise decrease in education level and self-assessed health and a stepwise increase in difficulty in making ends meet and number of hospital contacts and hospital admissions with increasing frailty status, $\mathrm{p}<0.0001$ for each comparison. Notably, $14.7 \%$ of those who were frail had no hospital contacts (table 3 ).

Frail persons had significantly higher prevalence of myocardial infarction, angina, migraine or headache, cancer, diabetes, hypertension, respiratory disease, depression, anxiety, kidney disease, asthma and dementia. Notably, $7.8 \%$ of those who were frail had none of these chronic diseases and $20.0 \%$ had just one which were: $43.2 \%$ arthritis, $21.1 \%$ hypertension, $8.4 \%$ migraine or headache, $7.4 \%$ cancer, $6.3 \%$ respiratory disease and $5.3 \%$ depression. The remaining chronic diseases were each represented by less than $2.5 \%$. Figure 1 shows the overlap between frailty and comorbidity.

Mean follow-up time was 1.13 years for all-cause mortality, giving a total of 8314568 person-years and 49 deaths $(0.7 \%)$. Compared with individuals who were non-frail, mortality was higher among those who were prefrail (HR: 2.90; 95\% CI: 1.30 to 6.43 ) or frail (HR: 8.21; $95 \%$ CI: 3.37 to 20.0 ) (table 4 ). 
Open access

Table 2 Association of demographic and health characteristics with frailty phenotype

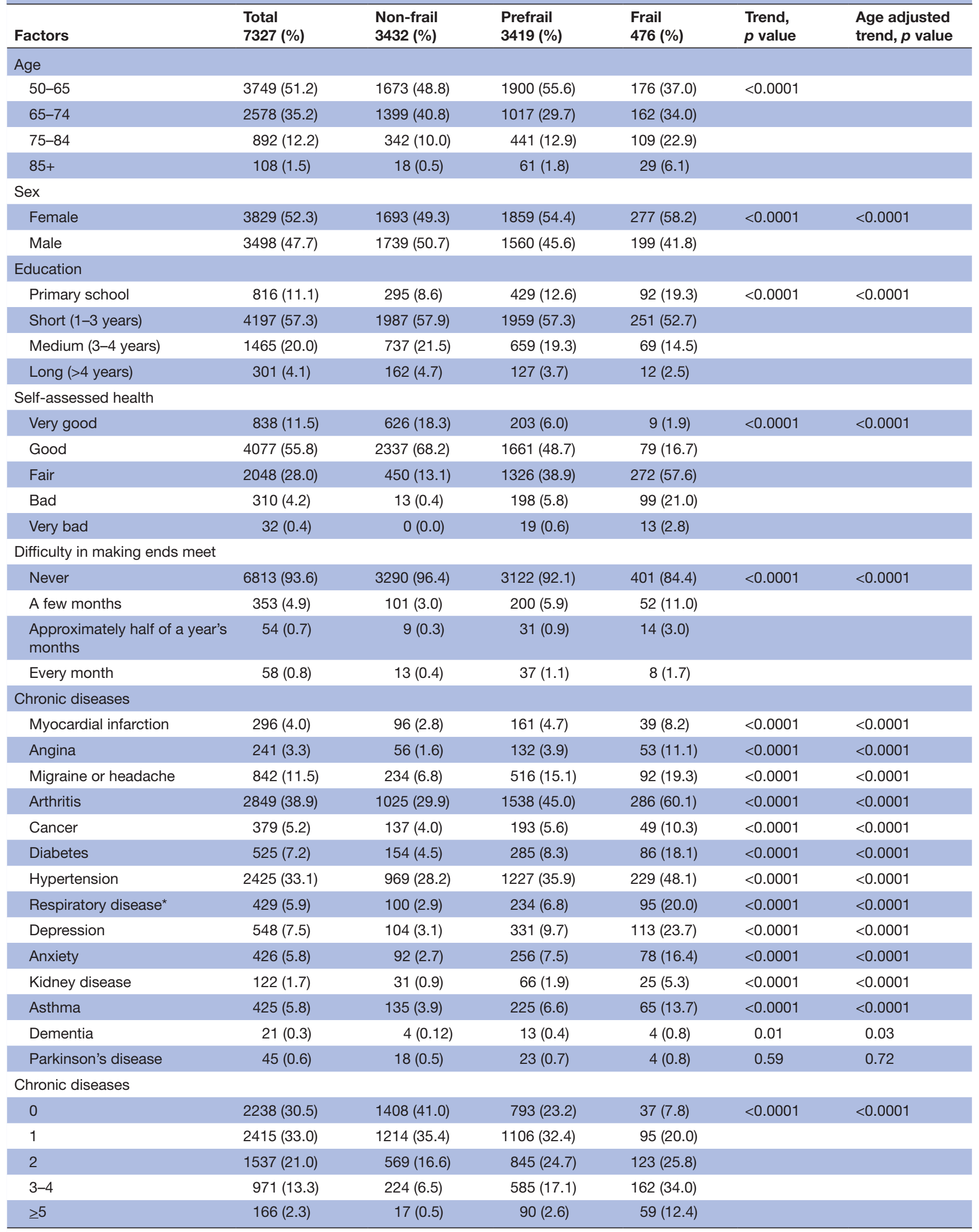

*Includes chronic bronchitis, emphysema, andchronic obstructive pulmonary disease. 


\begin{tabular}{|c|c|c|c|c|c|c|}
\hline Category & $\begin{array}{l}\text { Total } \\
7327(\%)\end{array}$ & $\begin{array}{l}\text { Non-frail } \\
3432(\%)\end{array}$ & $\begin{array}{l}\text { Prefrail } \\
3419(\%)\end{array}$ & $\begin{array}{l}\text { Frail } \\
476(\%)\end{array}$ & $\begin{array}{l}\text { Trend, } \\
p \text { value }\end{array}$ & $\begin{array}{l}\text { Age adjusted } \\
\text { trend, } p \text { value }\end{array}$ \\
\hline \multicolumn{7}{|c|}{ Ambulatory contacts } \\
\hline 0 & $3088(42.2)$ & $1628(47.4)$ & $1312(38.4)$ & $148(31.1)$ & $<0.0001$ & $<0.0001$ \\
\hline$<5$ & $3893(53.1$ & $1696(49.4)$ & $1908(55.8)$ & $289(60.7)$ & & \\
\hline $5-10$ & $335(4.6)$ & $105(3.1)$ & $193(5.6)$ & $37(7.8)$ & & \\
\hline$>10$ & $11(0.2)$ & $<5$ & $6(0.2)$ & $<5$ & & \\
\hline \multicolumn{7}{|c|}{ Hospital admissions } \\
\hline 0 & $3471(47.4)$ & $1865(53.3)$ & $1470(43.0)$ & $136(28.6)$ & $<0.0001$ & $<0.0001$ \\
\hline$<5$ & $2987(40.8)$ & 1299 (37.9) & $1464(42.8)$ & $224(47.1)$ & & \\
\hline $5-10$ & $727(9.9)$ & $235(6.9)$ & $402(11.8)$ & 90 (18.9) & & \\
\hline$>10$ & $142(1.9)$ & $33(1.0)$ & $83(2.4)$ & $26(5.5)$ & & \\
\hline \multicolumn{7}{|c|}{ Hospital stay, number of days } \\
\hline 0 & $3471(47.4)$ & $1865(54.3)$ & $1470(43.0$ & $136(28.6)$ & $<0.0001$ & $<0.0001$ \\
\hline$<5$ & 2329 (31.8) & $1062(30.9)$ & $1121(32.8)$ & $146(30.7)$ & & \\
\hline $5-10$ & $889(12.1)$ & $324(9.4)$ & $473(13.8)$ & $92(19.3)$ & & \\
\hline$>10$ & $638(8.7)$ & $181(5.3)$ & 355 (10.4) & $102(21.4)$ & & \\
\hline
\end{tabular}

\section{DISCUSSION}

In this study, we aimed at examining whether the frailty measurement used in a Danish population study was able to identify frail individuals. The frailty instrument used is based on the criteria characterising the frailty phenotype described by Fried $e t a l^{2}$ Our frailty measurement builds on the work by Santo-Eggimann et al, which showed that a subset of questions in the SHARE could be operationalised as a frailty measurement. ${ }^{8}$ Romero-Ortuno et al further developed this approach into the SHARE-FI and validated this instrument in several studies. ${ }^{91-23}$ The frailty items used in LOFUS were almost identical to those included in SHARE-FI.

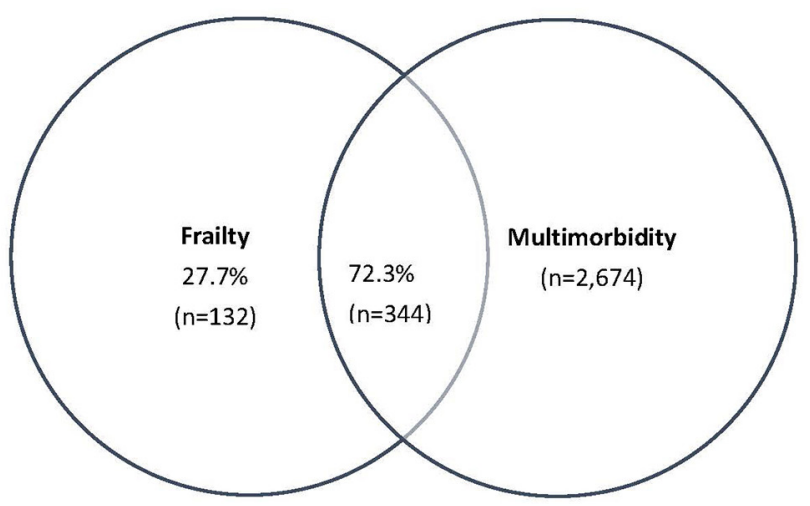

Figure 1 Venn diagram displaying extent of overlap of frailty with multimorbidity ( $\geq 2$ chronic diseases) in the Lolland-Falster Health Study. Total represented by 2674 individuals with frailty and/or multimorbidity. Percentages are percentages of individuals with frailty $(n=476)$. Frailty is based on the criteria characterising the frailty phenotype described by Fried et al. ${ }^{2}$
We have examined to what degree our frailty measurement was associated with factors already known to be associated with frailty: age, sex, multimorbidity, level of education, income insufficiency, self-assessed health and mortality.

Higher levels of education and income sufficiency were protective factors. Being female, of higher age and having more comorbidity were associated with increasing frailty. These findings are in agreement with a large number of other frailty studies. ${ }^{2}{ }^{16}$ Due to present lack of follow-up data, we could not test the predictive value concerning morbidity. We therefore decided to examine the association between frailty and number of hospitalisations in a 2-year period previously to the frailty measurement and found a significant trend with an increasing number of hospital contacts with increasing frailty. We only had a short follow-up period to examine mortality (1.13 years) but in spite of this, there was a significant increasing mortality rate with increasing frailty.

Overall, we found the prevalence of frailty to be $6.5 \%$. In the age group 50-64, it was $4.7 \%$ and in the $65+$, it was $8.4 \%$. This is an overall lower prevalence and a different pattern than what was seen in the group of Danish SHARE participants, in which the overall prevalence was $8.8 \%$, in

Table 4 Frailty status and mortality

\begin{tabular}{lcl}
\hline & $\begin{array}{l}\text { Number of } \\
\text { deaths }\end{array}$ & $\begin{array}{l}\text { Mortality } \\
\text { HR (95\% CI) }\end{array}$ \\
\hline $\begin{array}{l}\text { Non-frail (reference } \\
\text { group) }\end{array}$ & 8 & 1.00 \\
$\begin{array}{l}\text { Prefrail } \\
\text { Frail }\end{array}$ & 26 & $2.90(1.30$ to 6.43$)$ \\
\hline
\end{tabular}


the $50-64$ years $3 \%$, and in the $65+$ years old $12.4 \%$. The explanation might be that our study is taking place in a rural area with a relatively high proportion of socioeconomically deprived individuals in the younger age groups, while the Danish participants in SHARE were drawn randomly in order to select a representative sample of Danes from the whole country in these age groups. The population covered by LOFUS compared with the general Danish population has lower income, less education, higher burden of disease, higher prevalence of unhealthy lifestyle factors and an average life expectancy approximately 2 years lower than mean average life expectancy in Denmark (80.8 years) ${ }^{12}$ This could result in higher prevalence of frailty in the youngest age groups due to high burden of risk factors, and a lower prevalence in the older age groups due to selection leading to a healthy survivor effect. $^{24}$

The overall lower prevalence compared with SHARE might also be explained by characteristics of non-respondents in LOFUS. Halfway through the LOFUS data collection subjects with lower socioeconomic status and age above 80 were found to have lower participation rates compared with more well off and younger age groups (article in press). This implicates that our study may underestimate the prevalence of frailty.

The prevalence of $0,1,2,3,4$ or 5 frailty criteria was very similar to the findings by Fried $e t a l^{2}{ }^{2}$ The distribution of prevalence of the single frailty criteria has been differing in several studies. In our study, we found a very high prevalence of exhaustion $41.5 \%$ versus $17 \%$ in the study by Fried $e t a l^{2}$ and $27 \%$ in the cross European study by Santos-Eggimann et $a l^{8}{ }^{8}$ The way we measured exhaustion was exactly the same way as Santos-Eggiman by asking: 'In the last month or so, have you had too little energy to do things you wanted to do?' and in case of a 'Yes' this criteria was considered fulfilled. Fried et al used a more detailed report from the participants based on answers from two items from the modified 10-item Centre for Epidemiology Studies Depression Scale ${ }^{25}$ and this may explain some of the rather large difference in prevalence of the exhaustion criteria. We found a distribution of prevalence for the criteria slowness, weakness and physical activity similar to the findings by Eggimann et al but again somewhat different from the findings by Fried $e t$ $a l$. This may be due to the fact that Fried et al defined the cut-off values for these frailty criteria according to the population assessed by defining the criteria fulfilled if the values were included in the lowest quintile of the study sample distribution. Bouzòn et al recently showed that the standardisation to the population assessed makes a difference for the predictive ability of the frailty diagnosis. ${ }^{26}$

\section{Strengths and limitations}

Our study is a large population study with a representative sample for the geographical area covered by LOFUS. At the present, LOFUS is a cross-sectional study; however, due to the national health registries, we were able to follow the participants over a time period. The Danish registries are of high quality and the unique personal identification numbers of all Danish inhabitants made it possible to include valid data concerning morbidity (hospital contacts) and mortality. ${ }^{27}$ Due to the present lack of follow-up data concerning morbidity, we had to assess hospital contacts in a period before the frailty measurement instead of assessing the predictive ability concerning hospital contacts. However, frailty is considered a syndrome developing over time and not evolving as an acute event. We therefore consider the findings of association with previous hospital contacts equally valuable compared with an association with future hospital contacts.

\section{CONCLUSION}

We have described a frailty instrument that has only minor deviations from the frailty instrument developed in a large European population study, SHARE (SHARE-FI). Our frailty instrument shows the same characteristics as the SHARE-FI and other validated frailty measures concerning associations with sex, age, income insufficiency, education, comorbidity, self-assessed health, multimorbidity and mortality. Based on these findings, we consider our frailty measure a valid instrument.

\section{Twitter Randi Jepsen @RandiJepsen}

Contributors KKJ made substantial contributions in designing and performing the statistical analysis. RJ and MAL contributed in interpretation of data analysis. CN contributed to the design of the study and interpretation of data, and EH contributed to design of the study and interpretation of data analysis and made the first draft of the article. All authors performed critical revision of the article draft, approved the final version and agreed to be accountable for all aspects of the work.

Funding The authors have not declared a specific grant for this research from any funding agency in the public, commercial or not-for-profit sectors.

Competing interests None declared.

Patient consent for publication Not required.

Ethics approval LOFUS (SJ-421) as well as the present substudy on frailty (SJ-486) was approved by Region Zealand's Ethical Committee on Health Research. The Danish Protection Agency approved the LOFUS study (REG-24-2015).

Provenance and peer review Not commissioned; externally peer reviewed. Data availability statement No data are available.

Open access This is an open access article distributed in accordance with the Creative Commons Attribution Non Commercial (CC BY-NC 4.0) license, which permits others to distribute, remix, adapt, build upon this work non-commercially, and license their derivative works on different terms, provided the original work is properly cited, appropriate credit is given, any changes made indicated, and the use is non-commercial. See: http://creativecommons.org/licenses/by-nc/4.0/.

\section{REFERENCES}

1 Clegg A, Young J, Iliffe S, et al. Frailty in elderly people. Lancet 2013;381:752-62.

2 Fried LP, Tangen CM, Walston J, et al. Frailty in older adults: evidence for a phenotype. J Gerontol A Biol Sci Med Sci 2001;56:M146-56.

3 Mitnitski AB, Mogilner AJ, Rockwood K. Accumulation of deficits as a proxy measure of aging. ScientificWorldJournal 2001;1:323-36.

4 Xue Q-L, Bandeen-Roche K, Varadhan R, et al. Initial manifestations of frailty criteria and the development of frailty phenotype in the women's health and aging study II. J Gerontol A Biol Sci Med Sci 2008;63:984-90. 
5 Fried LP, Xue Q-L, Cappola AR, et al. Nonlinear multisystem physiological dysregulation associated with frailty in older women: implications for etiology and treatment. J Gerontol A Biol Sci Med Sci 2009;64:1049-57.

6 Szanton SL, Allen JK, Seplaki CL, et al. Allostatic load and frailty in the women's health and aging studies. Biol Res Nurs 2009;10:248-56

7 Bandeen-Roche K, Xue Q-L, Ferrucci L, et al. Phenotype of frailty: characterization in the women's health and aging studies. J Gerontol A Biol Sci Med Sci 2006;61:262-6.

8 Santos-Eggimann B, Cuénoud P, Spagnoli J, et al. Prevalence of frailty in middle-aged and older community-dwelling Europeans living in 10 countries. J Gerontol A Biol Sci Med Sci 2009;64:675-81.

9 Romero-Ortuno R, Walsh CD, Lawlor BA, et al. A frailty instrument for primary care: findings from the survey of health, ageing and retirement in Europe (share). BMC Geriatr 2010;10:57.

10 Macklai NS, Spagnoli J, Junod J, et al. Prospective association of the SHARE-operationalized frailty phenotype with adverse health outcomes: evidence from $60+$ community-dwelling Europeans living in 11 countries. BMC Geriatr 2013;13:3.

11 Börsch-Supan A, Jürges H. The Survey of Health, Aging, and Retirement in Europe - Methology. Mannheim Research Institute for the Economics of Aging, Mannheim University, 2005.

12 Jepsen R, Egholm CL, Brodersen J, et al. Lolland-Falster health study: study protocol for a household-based prospective cohort study. Scand J Public Health 2018:1403494818799613.

13 Collard RM, Boter H, Schoevers RA, et al. Prevalence of frailty in community-dwelling older persons: a systematic review. J Am Geriatr Soc 2012;60:1487-92.

14 Chang S-F, Lin H-C, Cheng C-L. The Relationship of Frailty and Hospitalization Among Older People: Evidence From a MetaAnalysis. J Nurs Scholarsh 2018;50:383-91.

15 Chang S-F, Lin P-L. Frail phenotype and mortality prediction: a systematic review and meta-analysis of prospective cohort studies. Int J Nurs Stud 2015;52:1362-74.
16 Romero-Ortuno R. Frailty index in Europeans: association with determinants of health. Geriatr Gerontol Int 2014;14:420-9.

17 Schmidt M, Pedersen L, Sørensen HT. The Danish civil registration system as a tool in epidemiology. Eur J Epidemiol 2014:29:541-9.

18 Lynge E, Sandegaard JL, Rebolj M. The Danish national patient register. Scand J Public Health 2011;39:30-3.

19 Avlund K, Lund R, Holstein BE, et al. Social relations as determinant of onset of disability in aging. Arch Gerontol Geriatr 2004;38:85-99.

20 Christensen U, Lund R, Damsgaard MT, et al. Cynical hostility, socioeconomic position, health behaviors, and symptom load: a cross-sectional analysis in a Danish population-based study. Psychosom Med 2004;66:572-7.

21 Romero-Ortuno $R$. The frailty instrument of the survey of health, ageing and retirement in Europe (SHARE-FI) predicts mortality beyond age, comorbidities, disability, self-rated health, education and depression. Eur Geriatr Med 2011;2:323-6.

22 Romero-Ortuno R. The frailty instrument for primary care of the survey of health, ageing and retirement in Europe predicts mortality similarly to a frailty index based on comprehensive geriatric assessment. Geriatr Gerontol Int 2013;13:497-504.

23 Romero-Ortuno R, O'Shea D, Kenny RA. The share frailty instrument for primary care predicts incident disability in a European populationbased sample. Qual Prim Care 2011;19:301-9.

24 Brown DM, Picciotto S, Costello S, et al. The healthy worker survivor effect: target parameters and target populations. Curr Environ Health Rep 2017;4:364-72.

25 Orme JG, Reis J, Herz EJ. Factorial and discriminant validity of the center for epidemiological studies depression (CES-D) scale. J Clin Psychol 1986;42:28-33.

26 Alonso Bouzón C, Carnicero JA, Turín JG, et al. The standardization of frailty phenotype criteria improves its predictive ability: the Toledo study for healthy aging. J Am Med Dir Assoc 2017;18:402-8.

27 Thygesen LC, Daasnes C, Thaulow I, et al. Introduction to Danish (nationwide) registers on health and social issues: structure, access, legislation, and archiving. Scand J Public Health 2011;39:12-16. 